\title{
NARRATIVAS ENTRECRUZADAS DE PROFESSORAS NEGRAS EM TERRAS DE GAUDÉRIOS
}

Treyce Ellen Silva GOULART ${ }^{\mathbf{1}}$

Universidade Federal Fluminense - UFF treyce.ellen@hotmail.com

Marcio Rodrigo Vale CAETANO ${ }^{2}$ Universidade Federal do Rio Grande mrvcaetano@gmail.com

Mary RANGEL ${ }^{3}$

Universidade do Estado do Rio de Janeiro mary.rangel@lasalle.org.br

Resumo: Este trabalho apresenta os caminhos investigativos percorridos a partir de narrativas autobiográficas de três professoras negras no município de Rio Grande/RS. A produção dos dados foi inspirada na metodologia de ateliês biográficos de projeto e deu-se por meio de encontros coletivos e individuais na escola em que atuavam, entre os anos de 2014 e 2015. As narrativas foram problematizadas a partir de um viés interseccional interpelado pelas perspectivas teóricopolíticas dos Estudos Feministas Decoloniais e Negros. As aproximações com as falas das docentes possibilitaram a compreensão dos diversos atravessamentos $e$ imbricação entre as questões de raça/racismo, gênero/sexismo $e$ classe/classismo de modo a percebermos estes elementos não enquanto estruturas sólidas, atômicas ou imutáveis, mas como um amálgama que é interpretado/interpelado $e$ interpreta/interpela as docentes em seus cotidianos.

Palavras-chaves: Feminismos. Docência. Narrativa autobiográfica. Decolonialidade.

\begin{abstract}
This paper presents the investigative paths covered by autobiographical narratives of three black female teachers in city Rio Grande/RS city. The production data was inspired by the methodology of biographical workshops and were obtained through collective and individual meetings at school in which the teachers worked, between 2014 and 2015. were problematized from a theoretical and political perspectives of Cultural, Feminist and Decolonial Studies and an intersectional bias. The approaches with the subjects' narrations provided an understanding of the various crossings and overlaps between the issues of race/racism, gender/sexism and class/classism in order to realize these elements not as solid, atomic or immutable structures, but as an amalgam it is interpreted/challenged and interprets/challenges the subjects in their daily lives.
\end{abstract}

Key-words: $\quad$ Feminisms. Teaching. Autobiographical Narratives. Decoloniality

\footnotetext{
${ }^{1}$ Mestrado em Educação pela Universidade Federal do Rio Grande, Brasil(2016).Bolsista FAPERGS da Universidade Federal do Rio Grande, Brasil.

2 mestrado e doutorado em educação pela Universidade Federal Fluminense (UFF). Docente na Universidade Federal do Rio Grande (FURG).

${ }^{3}$ Doutorado em Educação Brasileira pela Universidade Federal do Rio de Janeiro, Brasil(1990). Professor Titular da Universidade do Estado do Rio de Janeiro.
} 


\section{Introdução}

Ao tomar a interseccionalidade enquanto prerrogativa para a produção de dados, o presente artigo buscará refletir, a partir de narrativas autobiográficas de três professoras negras, os modos por meio dos quais as sujeitas ${ }^{4}$ localizam-se dentro do sistema de gênero colonial moderno. Nessa direção, nos interessa aqui relatar analiticamente os caminhos investigativos percorridos com as sujeitas da pesquisa a fim de que, por meio do entrecruzamento de suas narrativas, seja tensionado tal conceito. Dessa forma, alinhamos a proposta apresentada com os estudos decoloniais e feministas negros no sentido de, mais do que criticar a produção acadêmica inquirirmos o tipo de racionalidade que a retroalimenta.

Tal exercício remete ao reconhecimento do caráter político da produção de conhecimento científico e a urgência de que sejam criados mecanismos que permitam a auto representação das/os sujeitas/os de pesquisa. Nesse sentido, esses/as não são objetos ou meras fontes com as quais o/a pesquisador/a produz seus dados. São, sobretudo, interlocutores/as cujas falas também são interessadas, políticas e produtoras/produtos de redes de poder que organizam/hierarquizam as relações sociais. Por essas razões, para o debate proposto, foi necessária a utilização de metodologias que fossem em direção a essa perspectiva e, sobretudo, que possibilitassem momentos de fala e escrita de si e escuta de outrem (que, como veremos, também prevê o movimento de debruçar-se sobre si).

Durante a pesquisa, sobretudo a partir das teorizações sobre as narrativas autobiográficas e formação, promovidas por Marie-Christine Josso (2004) e Christine Delory-Momberger (2008) decidimos nos inspirar na metodologia dos ateliês biográficos de projeto, idealizada por essa última. Conforme a autora,

Ateliês biográficos de projeto [...] registram a "história de vida" em uma dinâmica prospectiva, unindo as três dimensões da temporalidade (presente, passado e futuro) e visam dar as bases para o futuro do sujeito e fazer emergir seu projeto pessoal. O ambiente mais favorável para trabalho é de doze pessoas no máximo. [...]. Os participantes tomam conhecimento antecipado do tema e dos objetivos da sessão. Os encontros desenvolvem-se em seis etapas, de acordo com um ritmo progressivo que corresponda a um envolvimento crescente, que é importante ser controlado por cada um. (DELORYMOMBERGER, 2008, p. 100)

\footnotetext{
4 Adotaremos a utilização do termo sujeita enquanto proposta de deslocamento do olhar generalizante e patriarcal ao chamar atenção para que a linguagem não é apenas um sistema estrutural independente de nossas interações uns/umas com os/as outros/as, mas sim local onde a colonialidade de gênero, de poder e do ser toma forma e nos formata. Assim, o termo sujeitas afirma às palavras no masculino sua corporalidade, parcialidade e intenção invisibilizadora. 
Este procedimento foi adotado como inspiração por apoiar-se sobre duas práticas complementares: a da autobiografia, ou seja, do trabalho realizado sobre si mesma a partir da fala que, dita ou escrita, é sempre um ato de escrita de si; e a da heterobiografia, isto é, o trabalho de escuta/leitura e compreensão da narrativa autobiográfica feita pela outra. Estas duas práticas, possibilitadas pelo espaço construído, objetivaram, também, a compreensão da fala autobiográfica da outra, sobretudo, a partir das construções de relações de sentido da ouvinte ou da leitora consigo mesma e com sua própria construção biográfica.

Cada uma das etapas foi repensada e adaptada às vicissitudes da investigação desenvolvida. Após o início das atividades de campo efetivamente, realizamos três encontros coletivos e seis encontros individuais. Todos os encontros foram gravados, com a autorização das professoras e totalizaram 12 horas e 40 minutos de gravação. Os encontros ocorreram na escola em que as docentes lecionam e o material foi transcrito e enviado para leitura/aprovação das professoras por e-mail. Além desse, também foi solicitado dois escritos. No primeiro, solicitamos que as docentes escrevessem uma breve autobiografia, em até duas folhas e outra, mais sofisticada e abrangente, em que, cada uma delas, responderia a pergunta: “Como me tornei aquilo que sou?”. A partir desses materiais, elencamos abaixo os elementos trazidos por cada sujeita para apresentar-se.

Luiza $^{5}$ retrata-se como uma mulher solteira, de 54 anos, filha, irmã, professora, especialista, militante. Tem sua narrativa marcada fortemente por uma trajetória de ascensão e acesso a bens de consumo. A sujeita migra, como sua autobiografia nos conta, de um contexto de extrema exploração da força de trabalho de sua mãe, ocupando na infância uma posição enquanto filha da empregada e atravessada de afetividades dentro da casa dos patrões desta, assim como apresenta os primeiros momentos em que identifica o racismo atravessado de questões de classe e gênero, na escola. A quase totalidade de sua fala busca afirmar um exacerbado orgulho de suas conquistas, a partir do acesso à Educação Superior, à prática política e pedagógica que tem garantido a ela a ampliação de suas redes, o que a sujeita interpreta enquanto um avanço quando contrapõe essa "abertura" ao passado (e aqui houveram várias referências à ditadura militar) já que agora é possível a ela falar de sua cultura e, sobretudo, ser ouvida. Luiza (re)afirma a

\footnotetext{
${ }^{5}$ Os nomes das docentes são fictícios. MARGENS - Revista Interdisciplinar Versão Digital-ISSN: 1982-5374
} 
necessidade de a escola "preparar cidadãs/ãos negras e negros que é para estar lá, lá em cima na pirâmide".

Beatriz narra-se como mulher, negra, solteira, filha, irmã, professora, militante. Com pouquíssimas exceções, usa maquiagem, utiliza roupas que denotam elegância, apresenta seus cabelos alisados/relaxados, loiros e curtos. Frequentemente, utiliza roupas/acessórios amarelas/os em referência à Oxum ${ }^{6}$, é altiva e suas colocações são feitas com seriedade. Em nossas conversas, recorrentemente, houve uma narrativa e projeção de si que se organizava em torno de um discurso vitorioso. De fato, Beatriz, quando possível, salientava sua não concordância com aquelas militâncias que apenas debruçam-se e produzem sobre a camada populacional negra que está nas favelas ou em uma situação socioeconômica desfavorável. Assim, advoga o reforço de elementos culturais africanos e afro-brasileiros enquanto forma de enfrentamento ao racismo e possibilidade de ascensão econômica.

Por fim, Sueli descreve-se como uma mulher negra, jovem, vice-diretora de escola, especialista, casada com um bombeiro, filha de um portuário e dona de casa, com uma situação financeira estável, mãe de uma menina, vigia de si, militante. Estes são os marcadores que apreendemos a partir da proposta de falar sobre seu trajeto de vida pessoal e profissional e, a partir deles, ela parece reivindicar legitimidade e coerência para sua narrativa. Por meio da noção de adequação vai delineando e justificando sua posição.

Como podemos perceber, ainda que as três sujeitas reconheçam-se enquanto professoras e mulheres negras não há nada de homogêneo nos arranjos de identificação que o grupo acessará para construir suas (auto)representações. Seus pontos de vista, tampouco, são estáticos e, nesse sentido, concordamos com Patrícia Hill Collins (2012) quando a autora reflete que, ainda que algumas mulheres negras compartilhem desafios comuns, esses podem ou não promover perspectivas similares, inclusive no que tange às táticas de enfrentamento/adequação ao sistema de gênero colonial moderno.

\footnotetext{
${ }^{6}$ Oxum é uma Orixá, entidade cultuada nas religiões de matriz africana, rainha da água doce, dona dos rios e cachoeiras. Oxum é a segunda esposa de Xangô e representa a sabedoria e o poder feminino. Além disso, é vista como deusa do ouro e do jogo de búzios. É a deusa do rio Oxum (ou Osun) que fica no continente africano, mais concretamente no Sudoeste da Nigéria. O arquétipo de Oxum é de uma mulher graciosa e elegante, que tem predileção por joias, perfumes e roupas. A figura de Oxum carrega um espelho na mão e é associada à água, ao amarelo e ao Sábado. 


\section{Desenvolvimento}

Com estas explanações, buscamos expor parte das teorias e reflexões que têm sido as lentes com as quais olhamos para a experiência de pesquisa, assim como informar sobre os caminhos trilhados durante este processo. Percebemos as interlocutoras da pesquisa enquanto três mulheres negras, intelectuais que têm produzido conhecimento implicado politicamente. Três mulheres diferentes, com idades, trajetória familiar, socioeconômica e cultural também diferentes que se encontram em determinado espaço tempo e, a partir deste território nada pacificado, criam estratégias de pertencimento, de existência atravessadas por suas corporalidades. Também entram nessa roda, interseccionalmente, as relações interpessoais, as noções sobre negritude, africanidade, raça, femininos e prática docente. Dessa forma, compreendendo que os discursos têm sido espaços de (im)possibilidades para as mulheres negras, propomos que nos ancoremos nessas narrativas de si para refletir de forma menos distorcida pela colonialidade os modos como as opressões sofisticam-se no cotidiano destas sujeitas.

Jurema Werneck ${ }^{7}$ fornece algumas pistas para pensarmos a reunião de mulheres negras em grupos engajados com a transformação social. A pesquisadora debateu, durante palestra, sobre o limitado número de produções que deem conta das trajetórias destes movimentos. Para ela, é necessário que, a priori, consideremos que as mulheres negras estiveram organizadas ao menos em cinco momentos históricos: a) ancestralidade: correspondendo às organizações matriarcais em África, antes do período colonial; b) tráfico negreiro: na resistência e articulações nas comunidades africanas, em resistência ao sequestro de homens e mulheres africanos/as; c) escravidão: rebeliões individuais e coletivas contra o sistema escravocrata, liderança de quilombos; d) pós-abolição: de escravizadas passaram a empregadas domésticas organizadas em torno da defesa de seus direitos, resistindo ao papel central dentro do mito da democracia racial por meio da mestiçagem; e) anos 1980: geração de Lélia Gonzales, Beatriz Nascimento, Rosália Lemos, pensadoras negras disputando o lugar de fala em oposição a um feminismo branco e ao machismo dentro do movimento negro, discutindo o bem viver e f) tempo presente: marcado notadamente pela geração de mulheres negras herdeiras dos espaços criados e ocupados por outras mulheres negras no passado, tais como a Universidade.

\footnotetext{
${ }^{7}$ A pesquisadora proferiu aula/palestra sobre o pensamento das mulheres negras na Diáspora durante o IX Curso de Atualização A Teoria e as Questões Políticas da Diáspora Africana nas Américas. O curso ocorreu no Rio de Janeiro, de 08 de junho a 17 de julho de 2015. 
Tais marcos remetem diretamente ao cenário brasileiro e, para Werneck, é a partir da inserção de mulheres negras no ambiente universitário que se começa a utilizar o termo feminismo negro. E, por isso, ressalta, considerando esta linha temporal, que, para além de definirmos um nome para o movimento atual, precisamos pensar o que este pode significar para o presente, para o futuro e também sua influência no olhar ao passado destas relações construídas. Dessa forma, pensar sobre os movimentos de mulheres negras nos leva a crer que, em qualquer espaço em que estivessem reunidas refletindo sua condição social, houve produção de determinado conhecimento, base para a criação de estratégias e articulações para resistência. É nesse sentido que atribuímos relevância às suas narrativas, localizadas e não generalizantes, para a construção de uma análise mais aprofundada das condições de subalternidade e resistência dentro do sistema colonial de gênero.

Conforme nos sublinha Delory-Momberger:

[...] a narrativa é não apenas o meio, mas o lugar: a história da vida acontece na narrativa. O que dá forma ao vivido e à experiência dos homens [e das mulheres] são as narrativas que eles[elas] fazem de si. Portanto, a narração não é apenas o instrumento da formação, a linguagem na qual se expressaria: a narração é o lugar no qual o indivíduo toma forma, no qual ele/a elabora e experimenta a história de sua vida. (2008, p. 56)

A narrativa autobiográfica instala um sistema de interpretação e construção que situa, une e faz significar os acontecimentos da vida como elementos organizados dentro de um todo. Ao mesmo tempo implica, por um lado, em um projeto de si (projeção e em um projetar-se enquanto possibilidade), dentro de uma construção biográfica cujos acontecimentos organizados puxam este/a sujeito/a para o futuro, o/a justificando retrospectivamente. Por outro lado, implica também na reflexividade biográfica em que o/a autobiógrafo/a representa sua vida enquanto um todo unitário e estruturado, articulando e atribuindo sentidos a cada experiência dentro do curso de sua vida. Sendo assim, compreendemos as narrativas enquanto construção de si a partir do revisitar, reorganizar e remexer com as experiências. Contudo, essas representações de si podem cristalizar significados em torno de uma identidade "mulher negra", por exemplo, ignorando os modos complexos como raça/classe/gênero estão imbricados nessas experiências.

No que tange ao conceito de raça, Quijano (2005) nos ajuda a refletir sobre as características da forma de poder estabelecida no que se convencionou chamar América 
a partir da invasão europeia. $\mathrm{O}$ autor, em um exercício de análise sobre as relações sociais pautadas na exploração com fins de acúmulo de renda por um grupo restrito, discorre sobre como estas estabeleceram a dinâmica relacional entre colonizadores e colonizados/as. Da mesma forma, debruçou-se sobre as relações dos "senhores" a partir da dominação/exploração da força de trabalho dos/as habitantes originais da América e, posteriormente, de homens e mulheres provenientes do continente africano transmigradas/os para trabalhos forçados nas colônias ibéricas.

Ainda, o pesquisador nos propõe a crítica mais aprofundada da construção das identidades, a partir de um viés decolonial, de forma relacional e opositiva, sublinhando a constituição do termo raça. Assim, ressalta a existência de uma Europa e de um europeu (no masculino) somente a partir da criação da América enquanto colônia:

Na América, a ideia de raça foi uma maneira de outorgar legitimidade às relações de dominação impostas pela conquista. A posterior constituição da Europa como nova identidade depois da América e a expansão do colonialismo europeu ao resto do mundo conduziram à elaboração da perspectiva eurocêntrica do conhecimento e com ela à elaboração teórica da ideia de raça como naturalização dessas relações coloniais de dominação entre europeus e não europeus. Historicamente, isso significou uma nova maneira de legitimar as já antigas ideias e práticas de relações de superioridade/inferioridade, entre dominantes e dominados. [...]. Desse modo, raça converteu-se no primeiro critério fundamental para a distribuição da população mundial nos níveis, lugares e papéis na estrutura de poder da nova sociedade. Em outras palavras, no modo básico de classificação social universal da população mundial. (QUIJANO, 2005, 107-108)

Este binarismo cartesiano, eurocêntrico, que nos traz Quijano, tem sido a base sobre a qual as diferentes identidades têm se construído, a partir do pensamento colonial, na relação de subalternização de um outro cuja inferioridade é naturalizada. Assim, estabelecem-se os conceitos de homem-mulher, branco-negro, senhor-escravo, adultocriança. Daí depreende-se e relacionam-se ideais eurocêntricos de modernidade ${ }^{8}$ para a concepção do mundo em que, em primeiro plano, a história da civilização humana é retratada como uma trajetória que parte de um estado de natureza e culmina na Europa; e, em segundo plano, são outorgadas enquanto diferenças de natureza (racial) e não de história do poder, as diferenças entre europeus e não europeus. Dessa maneira,

\footnotetext{
${ }^{8}$ A utilização do termo em caixa baixa busca, a partir de um viés decolonial (MIGNOLO, 2005; QUIJANO, 2005, LANDER, 2005 e DUSSEL, 2005) e de desobediência epistêmica (MIGNOLO, 2008), denotar a visão de modernidade não enquanto um período histórico, mas sim como fenômeno cultural e histórico específico, uma narrativa do capitalismo imperial e da modernidade/ colonialidade. Dessa forma, nega-se aqui esta narrativa hierarquizante e seu evolucionismo unilinear que passou a organizar e classificar o mundo a partir de valores eurocêntricos que se afirmavam universais. 
legitimava-se a dicotomização e a essencialização identitária. Assim, o primeiro componente é apresentado como o puro, ideal a ser alcançado, o modelo a ser copiado, a razão, enquanto que ao segundo resta a cópia, a incompletude, a animalidade, a natureza.

Nas relações desenvolvidas, foi forjada, possivelmente a partir de diferenças fenotípicas, a codificação das diferenças e a noção de superioridade branca, frente aos povos indígenas e, posteriormente, aos negros e amarelos. $\mathrm{O}$ autor aborda um cenário colonial em que a dominação/exploração esteve diretamente ligada ao binômio raça/trabalho. Nestes termos, com a divisão racial do trabalho, e a partir da expansão mundial (propiciada por séculos de exploração de trabalho gratuito de negros/as e indígenas) da dominação colonial, por parte da dita raça dominante, foi imposto o mesmo critério de classificação social a toda a população mundial em escala global.

\begin{abstract}
A classificação racial da população e a velha associação das novas identidades raciais dos colonizados com as formas de controle não pago, não assalariado, do trabalho, desenvolveu entre os europeus ou brancos a específica percepção de que o trabalho pago era privilégio dos brancos. A inferioridade racial dos colonizados implicava que não eram dignos do pagamento de salário. Estavam naturalmente obrigados a trabalhar em benefício de seus amos. Não é muito difícil encontrar, ainda hoje, essa mesma atitude entre os terratenentes brancos de qualquer lugar do mundo. E o menor salário das raças inferiores pelo mesmo trabalho dos brancos, nos atuais centros capitalistas, não poderia ser, tampouco, explicado sem recorrer-se à classificação social racista da população do mundo. Em outras palavras, separadamente da colonialidade do poder capitalista mundial. (QUIJANO, 2005, p. 110)
\end{abstract}

Tais características foram utilizadas para justificar a exploração e escravização de mulheres e homens africanas/os englobadas/os na categoria, criada com as relações colonialistas de poder, "negros/escravos" pelos "brancos/senhores". Estes termos têm uma construção identitária relacional, e, portanto, sempre atrelada a seu “oposto". Nesta relação atomizada, a mulher negra é uma impossibilidade. Isso se dá porque a colonialidade presente na linguagem atomizada nos apresenta uma lógica dicotômica em que conseguimos considerar apenas o ente dominante quando nomeamos algo. Portanto, quando nos referimos a "negro", logo pensamos em homens negros, e, quando é mencionada a figura da mulher, esta é branca ${ }^{9}$. Assim, nesta intersecção as mulheres negras "não teriam vez, nem voz", como diria Luiza. Nestes termos, a "interseccionalidade é importante quando mostra a falha das instituições em incluir discriminação ou opressão", contra mulheres negras. (LUGONES, 2014, p. 942).

\footnotetext{
9 Aqui não podemos perder de vista que tampouco esta mulher ou este negro serão membros da população de Lésbicas, Gays, Bissexuais, Transexuais e Travestis e que este marcador também é gerador de desigualdades e opressões. 
Em contraponto, Lugones sugere que, da mesma forma que a colonialidade do poder vai engendrar raça e classe, também ocorrerá com o conceito de gênero. Para a pesquisadora, a colonialidade

ha permeado todas y cada una de las áreas de la existencia social, constituyendo la forma más efectiva de la dominación social tanto material como intersubjetiva. Por lo tanto, «colonialidad» no se refere solamente a la clasificación racial. Es un fenómeno abarcador, ya que se trata de uno de los ejes del sistema de poder y, como tal, permea todo control del acceso sexual, la autoridad colectiva, el trabajo, y la subjetividad/intersubjetividad, y la producción el conocimiento desde el interior mismo de estas relaciones intersubjetivas. Para ponerlo de otro modo, todo control del sexo, la subjetividad, la autoridad, y el trabajo, están expresados en conexión con la colonialidad. (LUGONES, 2008, p. 79)

Nesse sentido, subjaz ao conceito de interseccionalidade uma percepção de adição/sobreposição entre raça, gênero e classe. Entretanto, o que Lugones nos propõe é a necessidade de pensarmos a sofisticação dessas relações de poder em uma estrutura que ela nomeia sistema de gênero colonial moderno. Sua análise objetiva nomear não somente uma classificação de povos em termos de colonialidade de poder e de gênero, mas sobretudo o "processo de redução ativa das pessoas, a desumanização que as torna aptas para a classificação, o processo de sujeitificação e a investida de tornar o/a colonizado/a menos que seres humanos”. (LUGONES, 2014, p. 939).

As discussões propostas pela autora no artigo Rumo a um feminismo decolonial respondem à pergunta cerne do discurso de Sojourner Truth ${ }^{10}$. Ao questionamento " Ain't I a woman?", ou seja, "E eu, não sou uma mulher?", Lugones informa que a resposta colonial seria "Não". No texto em questão, a autora sublinha, a partir de um ponto de vista decolonial das relações de gênero, que:

Começando com a colonização das Américas e do Caribe, uma distinção dicotômica, hierárquica entre humano e não humano foi imposta sobre os/as colonizados/as a serviço do homem ocidental. Ela veio acompanhada por outras distinções hierárquicas dicotômicas, incluindo aquela entre homens e mulheres. Essa distinção tornou-se a marca do humano e a marca da civilização. Só os civilizados são homens ou mulheres. Os povos indígenas das Américas e os/as africanos/as escravizados/as eram classificados/as como espécies não humanas - como animais, incontrolavelmente sexuais e selvagens. [...] A imposição dessas categorias dicotômicas ficou entretecida com a historicidade das relações, incluindo as relações íntimas. (LUGONES, 2014, p. 936)

Nestes termos, a brutalidade do sistema colonial produzia ativamente por meio de seus discursos e práticas a não existência e a desumanização das populações escravizadas.

\footnotetext{
${ }^{10}$ Sojourner Truth era uma defensora dos direitos das mulheres e proferiu um discurso durante o Women Rights Convention no ano de 1851, em Ohio. Em sua fala, Truth questiona e expõe a desigualdade e hierarquia construída dentro da categoria "mulher". 
Para a autora, assim como para Quijano (2005), a hierarquia dicotômica entre o humano e o não humano é a dicotomia central da modernidade. Ao mesmo tempo, produzia e produz, por meio da colonialidade, sujeitos/as com pontos de vista prismados pela relação de opressão $\leftarrow \rightarrow$ resistência neste sistema. A partir dessas reflexões, passamos às narrativas das sujeitas interlocutoras dessa pesquisa e que nos apresentam os modos como elas organizam suas (auto)representações.

Como eu tinha te falado... eu ...mulher e negra... para as coisas que eu vivenciei até agora pesou muito mais o ser negra do que o ser mulher. Pesou muito mais assim. Acho que ficou muito mais evidente. Talvez se fosse só mulher e não fosse negra não teria pesado tanto. Acho que a questão racial ainda sobrepõe a questão de gênero. Pelo menos assim, comigo... numa questão de história. Até porque eu vivo em um... a minha profissão é uma profissão feminina. Então, eu não vejo tanto essa dificuldade na minha trajetória profissional. Do negro eu já acho que pesa muito mais do que ser mulher. [...] - Professora Sueli

[...] Em relação ao cabelo principalmente eu acho que a gente tem que se sentir bem como a gente tá. Então não adianta eu andar com um black se eu não me sentir bem. Eu acho que a minha postura, o que eu acredito, as coisas que eu fiz ao longo dos anos com os alunos falam muito mais do que eu fazer uma chapinha, ou uma progressiva no cabelo. O meu cabelo... não e só o meu cabelo que me identifica. Tem várias outras coisas que me identificam. Não adianta eu colocar um enfeite no cabelo porque todos os afros estão usando se eu não me sinto bem com aquilo ali. Eu acho legal, eu acho que a gente tem que se aceitar, só que eu venho de uma outra geração... que tudo era feio, que teu cabelo é feio, teu nariz é feio, tua pele é feia. Vocês são burros, vocês não sabem de nada, vocês são quase macacos. Então...eu estou impregnada com isso daí. Mas não é isso que me faz ter o cabelo assim ou assado. Acho que é tu olhar e te gostar. Eu acho que eu sou pequenininha, se eu ficar com cabelão, acho que eu viro cabelo. E eu me sinto melhor com cabelo mais, mais... não é liso para parecer outra pessoa, uma outra coisa. Mas é que eu me sinto melhor assim. Eu me sinto melhor assim. [...] Talvez daqui uns anos mais tu me encontre com o cabelo. Que eu supere isso aí. Ou não. Eu não uso o cabelo natural do jeito que eu quero... porque os outros vão falar que eu estou com um cabelão. Eu não me sinto bem. Eu não me sinto à vontade. Eu não gosto. Eu não acho... me incomoda. Então para que eu vou usar uma coisa que me incomoda? Em contrapartida, tem gente que tem todo um visual e black e não tem a prática. Usa dread, usa não sei quê, mas não está vinculado ao movimento, não faz nada para as coisas se modificarem. [...] - Professora Sueli

Os/as sujeitos/as não vivem em um vácuo existencial em que definem quem serão.

Se, por um lado, somos seres afetados pelas práticas discursivas que buscam nos moldar e configurar dentro das normatizações, também não somos idênticos/as àquilo que a hegemonia busca projetar sobre nós. Existem diversos discursos e engendradas estruturas de subjetivação buscando, a todo tempo, conformar os mundos de vida, matrizes de nosso processo de biografização. Estas/es são estruturantes porque afetam o projeto individual que temos sobre nós mesmos/as enquanto seres inseridos em um espaço-tempo.

Ao projetar o passado pela construção biográfica, cada acontecimento, cada personagem, cada fala pronunciada encontra sua função e seu sentido, segundo o lugar que ocupa na conexão do projeto de si e dos projetos particulares que puxam a "história" para seu final, isto é, para a realização hipotética daquilo que a projeta para o possível e que a justifica retrospectivamente. A "história de vida" não é a história da vida, mas a ficção apropriada pela qual o sujeito se produz como projeto dele mesmo. Só pode haver sujeito de uma história a ser feita, e é, à emergência desse sujeito, que intenta sua história e que se 
experimenta como projeto, que responde o movimento da biografização. (DELORY-MOMBERGER, 2008, p. 65-66).

Uma vez que este projeto é o espaço em que atuamos para cada vez mais nos aproximarmos dessa projeção, as relações de poder agem exatamente sobre a moldagem deste projeto, definindo os modelos nos quais devemos nos espelhar ao nos representarmos. Nesta lógica de subjetivação, se o modelo binário de homem e mulher tem em seu cerne a branquitude, a heterossexualidade e a lógica burguesa, são estes os parâmetros com os quais nos relacionamos em um movimento de aproximação/negação. Este seria o indivíduo-projeto ideal a ser referenciado.

Eu acho que eu já passei mais preconceito... já senti mais discriminação por ser negra do que por ser mulher. Acho que a questão da negritude... ou por ser mulher. Acho que eu sou mais negra do que mulher. Eu acho. Sou mais negra do que mulher. Não sei... - Professora Luiza

Faz a tua parte bem... eu faço a minha parte bem... e vai ficar bom para todos. Isso que eu acho. [...] E sofrimento eu não tenho. Hoje eu não tenho sofrimento... tenho orgulho, felicidade. Essa questão racial... temos que avançar? Muito. Já avançamos bastante. Quer ver uma coisa que me deixa muito orgulhosa, isso já foi motivo de várias discussões. Quer ver eu chegar em um lugar... outro dia estávamos em um lugar aqui na comunidade, que é de tábuas, lanches, não sei que mais... outro dia lá no restaurante e que aí fomos só negros. Daí deu problema. Sempre dá problema. Fomos eu Sueli, minha irmã e outra amiga, que começou comigo a pós. Eu olhava assim... e eu estava orgulhosa de nós estarmos ali... os negros bem arrumados, interagindo... cada um com seu celular... aí tira foto, aquela coisa toda, coloca no face(book) e nós estávamos ali. E daqui a pouco se tu fores puxar quando que nós iríamos? Iríamos. De repente, para servir. Não que seja desonra. Porque se eu cheguei até aqui foi graças a essas profissões. Mas nós estávamos ali... nós fizemos acontecer. E estamos tendo condições de participar disso aí. Os negros bemcomportados... bebendo... conversando... quem toma cerveja, quem toma vinho... para mim, isso é muito. Porque para mim o que eu sou, eu já digo. Sou negra. Negra. Mas como eu sou do português para mim negra já é mulher. [...]-Professora Luiza

Conforme Guattari e Rolnik, assim como existe a linguagem enquanto fato social e o indivíduo falante, acontece também com a subjetividade. A subjetividade circula nos conjuntos sociais de diferentes formas:

[...] ela é essencialmente social, e assumida e vivida por indivíduos em suas experiências particulares. O modo pelo qual os indivíduos vivem essa subjetividade oscila entre dois extremos: uma relação de alienação e opressão, na qual o indivíduo se submete à subjetividade tal como a recebe, ou uma relação de expressão e de criação, na qual o indivíduo se reapropria dos componentes da subjetividade, produzindo um processo que eu chamaria de singularização. (GUATTARI; ROLNIK, 2005, p. 42)

Se nos aproximamos do que escreve Christine Delory-Momberger (2008) sobre a biografização, esta primeira forma descrita por Guattari e Rolnik é improvável. O sujeito não pode ser considerado como agente passivo, que recebe e reproduz automaticamente os discursos que interpelam sua produção de si. Ao narrar-se, mesmo antes de falar, e ao escrever-se, antes mesmo de escrever, o indivíduo põe em movimento tanto elementos 
psíquicos, suas memórias, redes de parentesco, o que compõe o seu mundo de vida como também, simultaneamente, movimenta estas redes de subjetivação. Ou seja, o processo de construção do eu, é sempre implicado, atravessado nas rasuras entre o indivíduo e o meio social em que se insere.

Tu vê os olhares, os buchichos, mas não dá pra dar muita bola. Se eu fosse dar importância pra tudo isso aí eu não chegaria onde eu cheguei. Iria estar dentro de casa, escondida dentro do armário chorando. Então, vai. Toca a frente, porque o tempo passa, não volta atrás e tu tem que correr. Porque o tempo passa e tu tens que correr, porque tu não podes ficar pra trás. E, quando eu digo "tu não podes ficar pra trás", o negro não pode ficar para trás e tu não pode ficar pra trás como cidadão. É um direito teu de correr atrás de seus sonhos, de seus ideais, de seus objetivos. Então, tu vai correr, tem que correr, porque se tu ficar esperando pelo outro, nada vai acontecer. - Professora Beatriz

[...] Nós vivemos em uma sociedade em que o fato de ser mulher já é algo muito pesado, onde a mulher não pode isso, não pode aquilo. Mulher é chamada de várias determinações pejorativas em determinado momento... então isso incomoda. Porque mesmo nós estando em uma sociedade onde se tem maior abertura para as mulheres, onde as mulheres estão atuando em vários segmentos, ainda existe esse ranço que várias pessoas ainda carregam consigo... essa ideia que foi colocada alguns anos atrás que mulher não podia fazer quase nada. Isso incomoda bastante, atrapalha bastante, mas não me impede de seguir adiante. Bem pelo contrário. Me dá mais vontade de mostrar que por ser mulher eu posso fazer a mesma coisa, com a mesma capacidade, com a mesma desenvoltura, ou talvez até mais. Não quero ser radical e dizer que a mulher é melhor. Não. A mulher pode e deve fazer tudo aquilo que ela quiser fazer, ela não pode se colocar abaixo em uma situação. Então, dentro da nossa sociedade ainda tem muito para ser vencido. Eu creio que eu venci bastante essa função de ser mulher em uma sociedade machista e isso aí é algo que dá força. Para mim, Beatriz, isso me dá força. Eu vou adiante. Isso é uma história pessoal minha. Em relação a ser negra, não tive grandes dificuldades. Creio eu, outras mulheres negras teriam ou tenham. Mas eu não tive grandes dificuldades por ser negra. Isso eu não tive, dizer que eu não venci, que não fiz isso ou aquilo porque era negra. Muito pelo contrário. Eu fiz, faço e vou continuar fazendo. Independente de ser mulher, negra, pobre ou qualquer tipo de identificação. Isso não é impeditivo para alguém crescer e evoluir ao longo da vida. Ser mulher e ser mulher negra não contraria muito a minha forma de viver. Eu vivo, vivo muito bem, independente de ser negra, loira, ou magra, gorda, alta, baixa. Então, a questão que deve ser trabalhada é a questão da negritude, da identidade da mulher negra, para valorizar. Mas a mim a questão de ser negra não me bateu, não me entristeceu e nem foi impeditivo para chegar onde eu cheguei. [...] - Professora Beatriz

Estes apontamentos circundam e dão sentido à reprodução de discursos que constroem os corpos negros enquanto fortalezas, passíveis de suportar constantes exigências de resiliência. Esta representação atravessa cada relação estabelecida, amizades, relacionamentos afetivo-sexuais, redes de militância no movimento negro ou feminista. E, ao criarem tal projeção, também suas (auto)representações.

Nesses termos, concordamos quando Butler (1987) afirma que não se torna mulher, simplesmente. Não se torna mulher a partir do nada, a partir de algo que transcende a existência corpórea e na sociedade. Os elementos escolhidos para elencar enquanto identificação são aqueles disponibilizados por uma cultura que antecede a essa escolha. Existe uma série, pré-determinada, de elementos a serem selecionados para a 
construção, de coerência/linearidade ilusória, desta narrativa identitária. Quando, por outro lado, tomamos a frase de Lélia Gonzalez “(...) a gente nasce preta, mulata, parda, marrom, roxinha dentre outras, mas tornar-se negra é uma conquista."; este tornar-se negra é, tanto quanto ou semelhantemente ao gênero, "lugar dos significados culturais tanto recebidos como inovados" (BUTLER, 1987). Há, de fato, espaço para escolhas, mas a seleção ocorre entre aspectos de identificação dentre o que está disponibilizado enquanto possibilidades de representações, que interpelam/atravessam/atropelam esse contar de si, sobre o lugar ocupado socialmente. Ou seja, conforme nos salienta Hall (2012), a forma como somos representadas/os tem relação direta na maneira como representamo-nos.

Logo, não há nada de natural em ser mulher negra e, tampouco, nas relações que logram estabelecer entre si. Estas construções dão-se, sobretudo, e é o que buscamos afirmar com as discussões propostas até o momento, a partir de um terreno de resistência. Este termo é entendido enquanto "a tensão entre a sujeitificação (a formação/informação do sujeito) e a subjetividade ativa, aquela noção mínima de agenciamento necessária para que a relação opressão $\leftarrow \rightarrow$ resistência seja uma relação ativa" (LUGONES, 2014, p. 940). Portanto, os pactos possíveis precisam ser eminentemente políticos, interessados, imbricados pelas trajetórias pessoais. Assim, o que negritamos é este processo de construção de subjetividades sempre afetado, produzido nos entrecruzamentos individuais e coletivos.

\section{Conclusão}

Raça, gênero e classe não são categorias atomizadas, duras, impermeáveis e separáveis tornando impossível questionar a partir de um caso de opressão patriarcal racista qual operador foi responsável por determinado episódio, qual a projeção (machista, racista ou de classe) estava sendo realizada naquele momento sobre as corporalidades. Da mesma forma, com as/os autoras e autores citadas/os, este ponto de vista, leva-nos a desconfiar do conceito de interseccionalidade quando considerado enquanto sobreposição de opressões. Acreditamos que as estruturas se imbricam, contaminam e movimentam em um sistema de gênero colonial moderno. Por esta razão, não serão pontos pacíficos os elementos que as sujeitas que ocupam esse locus fraturado considerarão predominantes ou urgentes para as escolhas e táticas cotidianas. 
Foi exatamente nestas histórias e no debruçar sobre si que fomos encontrando os resquícios daquilo que as autoras/es citadas/os neste texto identificam enquanto colonialidade do gênero. E, para além desta aproximação, o que o chão da pesquisa permitiu compreender, foram os modos pelos quais as interlocutoras organizaram-se em torno de projetos políticos diferentes a partir de um contexto regional gaúcho de negação/invisibilização absoluta. É deste contexto que decorre, acreditamos, as escolhas políticas destas sujeitas na valorização/positivação/visibilização daquilo que reconhecem enquanto africanidade ou afrobrasilidade. Ao mesmo tempo em que estas escolhas parecem cristalizar estas significações/apropriações também mantem intacta, ao referenciarem, mesmo que de forma oposta, a hegemonia dos valores da branquitude.

Por outro lado, a adequação dentro de um sistema de classes garantido pelo estado democrático de direito vigente foi apresentada pelas três sujeitas, mesmo que diferentemente, enquanto um caminho possível para o enfrentamento do racismo. De fato, o que suas escolhas parecem reforçar é a complexidade deste amalgama de opressões em que, muitas vezes, a dureza do racismo, que potencializa a transformação das diferenças em desigualdade, tenta esconder as engrenagens do classismo e do sexismo também sustentáculos desse sistema.

\section{Referências}

BUTLER, Judith. Variações sobre sexo e gênero - Beauvoir, Wittig e Foucault. In: BENHABIB, S. \& CORNELL, D. (Orgs.). Feminismo como crítica da modernidade. RJ: Editora Rosa dos Ventos, 1987.

COLLINS, Patrícia H. Rasgos distintivos del pensamiento feminista negro. In: JABARDO, Mercedes (ed.). Feminismos negros: uma antologia. Traficantes de Sueños, 2012. Disponível em: <http://www.traficantes.net/sites/default/files/pdfs/Feminismos\%20negros-TdS.pdf $>$. Acesso em: 01 fev. 2017

DELORY-MOMBERGER, Christine. Biografia e educação: figuras do indivíduoprojeto. RN: EDUFRN; SP: Paulus, 2008.

DUSSEL, Enrique. Europa, modernidade e eurocentrismo. In: A colonialidade do saber: eurocentrismo e ciências sociais. Buenos Aires: CLACSO, 2005.

GUATTARI, Felix e ROLNIK, Sueli. Micropolítica - Cartografias do desejo. Petrópolis, RJ: Vozes, 2005

HALL, S. Quem precisa de identidade? In: SILVA, T. T. da. Identidade e diferença: a perspectiva dos estudos culturais. 12a ed. Petrópolis, RJ: Vozes, 2012. 
JOSSO, Marie-Christine. Histórias de vida e formação. São Paulo: Cortez Editora, 2004.

LANDER, Edgardo. Ciências sociais: saberes coloniais e eurocêntricos. In: A colonialidade do saber: eurocentrismo e ciências sociais. In: A colonialidade do saber: eurocentrismo e ciências sociais. Buenos Aires: CLACSO, 2005.

LUGONES, María. Rumo a um feminismo decolonial. Estudos Feministas, Florianópolis, 22(3):935-952, setembro-dezembro/2014. Disponível em: $<$ http://www.scielo.br/scielo.php?pid=S0104-

026X2014000300013\&script=sci_arttext>. Acesso em: 13 fev. 2017.

Colonialidad y género. In: Tabula Rasa. Bogotá - Colombia, n. 9, p. 73-101, juldic., 2008.

MIGNOLO, Walter. Desobediência epistêmica: a opção descolonial e o significado de identidade em política. Cadernos de Letras da UFF - Dossiê: Literatura, língua e identidade, no 34, p. 287-324, 2008. Disponível em: <http://www.uff.br/cadernosdeletrasuff/34/artigo18.pdf>. Acesso em: 10 jan. 2017.

A colonialidade de cabo a rabo: o hemisfério ocidental no horizonte conceitual da modernidade. In: A colonialidade do saber: eurocentrismo e ciências sociais. Buenos Aires: CLACSO, 2005.

QUIJANO, Aníbal. Colonialidade do poder, eurocentrismo e América Latina. In: A colonialidade do saber: eurocentrismo e ciências sociais. Buenos Aires: CLACSO, 2005. 